disease process and are likely to pave the way towards identifying disease-biomarkers for early-diagnosis of LN.

\section{PREDICTORS OF EARLY RESPONSE TO RITUXIMAB IN SYSTEMIC LUPUS ERYTHEMATOSUS (SLE): RESULTS FROM THE BRITISH ISLES LUPUS ASSESSMENT GROUP BIOLOGICS REGISTER (BILAG-BR)}

${ }^{1,2} \mathrm{~S}$ Nesbit*, ${ }^{2} \mathrm{E}$ Sutton, ${ }^{2} \mathrm{E}$ McCarthy, ${ }^{2} \mathrm{~J}$ Reynolds, ${ }^{2} \mathrm{~B}$ Parker, ${ }^{1} \mathrm{E}$ Morand, ${ }^{2} \mathrm{BILAG}-$ BR Consortium, ${ }^{2}$ Bruce. ' School of Clinical Sciences at Monash Health, Monash University, Melbourne, Australia; ${ }^{2}$ Centre for Musculoskeletal Research, University of Manchester, Manchester, UK

\subsection{6/lupus-2017-000215.300}

Background and aims The anti-CD20 agent rituximab (RTX) is generally reserved for the treatment of refractory SLE. Whist response is variable no clear predictors of early response have been confirmed. We aimed to explore factors that predict early response to RTX in a nationwide cohort of patients receiving their first RTX course.

Methods The BILAG-BR has recruited patients with refractory SLE starting RTX in the UK since Sept 2010. For this analysis we included patients who received RTX up to November 2015, had active disease at baseline, and had disease activity indices reported at baseline and 6 months. Response was defined as improvement of all active BILAG 2004 systems with no worsening in other systems or SLEDAI-2K; and no increase in glucocorticoid dose at 6 months.

Results In 197 patients $(90.36 \%$ females) 99 (50.8\%) responded at 6 months. In a multivariable model with imputation for missing variables, concomitant IV cyclophosphamide and higher baseline oral glucocorticoid dose were associated with better response. A higher baseline global BILAG-2004 score was associated with lower rates of response (Table 1).

Conclusions Early response to RTX in refractory SLE was associated with use of concomitant cyclophosphamide, higher glucocorticoid doses and lower baseline disease activity. Serology and demographic factors did not predict response. Understanding how concomitant therapy improves longer-term responses and identifying novel biomarkers of response will improve patient selection and overall outcomes for patients receiving this therapy.

Abstract 300 Table 1 Multivariable imputed model after backwards stepwise regression

\begin{tabular}{llll}
\hline Baseline factor & Odds ratio & $95 \% \mathrm{Cl}$ & $\mathbf{p}$ \\
\hline $\begin{array}{l}\text { Concomitant } \\
\text { cyclophosphamide }\end{array}$ & 4.50 & $(1.77,11.43)$ & 0.002 \\
$\begin{array}{l}\text { Global BILAG at } \\
\text { baseline }\end{array}$ & 0.96 & $(0.93,0.99)$ & 0.007 \\
$\begin{array}{l}\text { Baseline oral } \\
\text { steroid dose }\end{array}$ & $1.03^{*}$ & $(1.00,1.06)$ & 0.033 \\
\hline
\end{tabular}

*per $1 \mathrm{mg}$ increase in daily oral steroid dose. For every $10 \mathrm{mg}$ daily increase, OR 1.30

\section{EVIDENCE FOR A PRO-INFLAMMATORY AS WELL AS PROTECTIVE ROLE FOR IL-17A IN PATIENTS WITH SYSTEMIC LUPUS ERYTHEMATOSUS}

${ }^{1} \mathrm{~W}$ Raymond*, ${ }^{2} \mathrm{G}$ Ostli-Eilertsen, ${ }^{1} \mathrm{~S}$ Griffiths, ${ }^{1,2} \mathrm{~J}$ Nossent. ${ }^{1}$ The University of Western Australia, School of Medicine- Rheumatology section, Perth, Australia; ${ }^{2}$ Arctic University Norway, Dept Internal Medicine - Bone and Joint group, Tromso, Norway

\subsection{6/lupus-2017-000215.301}

Background and aims The successful application of IL-17 inhibitors in a number of chronic inflammatory diseases has increased interest for the role of IL-17 in other conditions. We investigated the clinical associations for the predominant family member IL-17A in patients with Systemic Lupus Erythematosus (SLE).

Methods Cross-sectional study of SLE patients $(n=102$, age 49, $86 \%$ female) recruited from a regional registry. IL-17A levels were determined by immunoassay, disease activity by SLEDAI-2K and cumulative damage by SLICC-DI scores. Nonparametric techniques were used to examine the association between IL-17A and disease activity, autoantibody profiles and damage development in SLE patients and for comparisons with healthy controls $(n=31)$.

Results SLE patients had higher IgG levels, lower T cell and B cell counts, but median IL-17A levels did not differ from controls (28.4 vs. $28.4 \mathrm{pg} / \mathrm{ml}, \mathrm{p}=0.9)$.

In SLE patients, IL-17A levels did not correlate with SLEDAI-2K or SDI, but were inversely related with systolic blood pressure $(\mathrm{r}=-0.31, \mathrm{p}=0.02)$, years smoking $(\mathrm{r}=-0.23$, $\mathrm{p}<0.001)$, cumulative heart $(\mathrm{r}=-0.24, \mathrm{p}=0.03)$ and malignancy damage $(\mathrm{r}=-0.18, \mathrm{p}=0.06)$.

Serological correlations for IL-17A existed with levels of IgG $(r=0.21, p=0.05)$, hs-CRP levels $(r=0.28, p<0.01)$, proteinuria $(\mathrm{r}=0.64, \mathrm{p}=0.004)$ and pre-albumen $(\mathrm{r}=-0.22$, $\mathrm{p}=0.03)$.

Longitudinal data showed only modest fluctuations in $17 \mathrm{~A}$ levels, unrelated to SLEDAI-2K

Conclusions These data indicate that while IL-17A participates in the inflammatory process in SLE, it also seems to serve a protective purpose in reducing heart disease and cancer in SLE. This dual role is consistent with experimental and clinical data and raises concerns about inhibting IL-17 in SLE patients.

\section{SERUM CYTOKINE ANALYSIS AND TRANSCRIPTIONAL BLOOD PROFILING REVEAL AN ASSOCIATION BETWEEN IL-3 AND IFN IN HUMAN SLE}

${ }^{1} \mathrm{~S}$ Oon*, ${ }^{2} \mathrm{~K}$ Monaghan, ${ }^{2} \mathrm{M} \mathrm{Ng},{ }^{3} \mathrm{~A}$ Hoi, ${ }^{3} \mathrm{E}$ Morand, ${ }^{2} \mathrm{~N}$ Wilson, ${ }^{1} \mathrm{I}$ Wicks. ${ }^{1}$ The Walter and Eliza Hall Institute of Medical Research, Inflammation, Parkville, Australia; ${ }^{2}$ CSL Limited, Pre clinical biology, Parkville, Australia; ${ }^{3}$ Monash University, Medicine, Melbourne, Australia

\subsection{6/lupus-2017-000215.302}

Background and aims IFN $\alpha$, produced by plasmacytoid dendritic cells (pDCs) is a major contributor to SLE pathogenesis. IL-3 promotes pDC survival, but its role in SLE has not been well characterised. This study investigated serum IL-3 and IFN $\alpha$ levels, and a whole blood 'IL-3 gene signature' in human SLE.

Methods Serum cytokine levels were measured by ELISA in $\mathrm{n}=42$ SLE donors from The Royal Melbourne Hospital and $n=44$ healthy donors (HD). IL-3 upregulated genes were determined by RNASeq of HD whole blood (WB) stimulated 